Research Article

\title{
Reform of the Practice Teaching System of Entrepreneurship Education Based on 5G Fog Computing in Colleges and Universities
}

\author{
Feiping Liu $\mathbb{D}^{1,2}$ Qiuling Gong $\mathbb{D}^{3}{ }^{3}$ and Junjie Zhou ${ }^{4}$ \\ ${ }^{1}$ School of Management, Wuhan University of Technology, Wuhan 430070, Hubei, China \\ ${ }^{2}$ PE Department, Wuhan Institute of Technology, Wuhan 430215, Hubei, China \\ ${ }^{3}$ PE Department, Zhongnan University of Economics and Law, Wuhan 430073, Hubei, China \\ ${ }^{4}$ Department of Information Science and Technology, Wenhua College, Wuhan 4300074, Hubei, China \\ Correspondence should be addressed to Feiping Liu; 05090601@wit.edu.cn and Qiuling Gong; lfp9095@163.com
}

Received 21 August 2021; Accepted 21 September 2021; Published 6 October 2021

Academic Editor: Punit Gupta

Copyright (C) 2021 Feiping Liu et al. This is an open access article distributed under the Creative Commons Attribution License, which permits unrestricted use, distribution, and reproduction in any medium, provided the original work is properly cited.

\begin{abstract}
Innovation is inevitable for economic development of the China and even the world, and entrepreneurship education is also an important topic for educators at home and abroad. It is an important issue for the sustainable development and effective operation of industry and education to establish an integrated support system of industry and education in universities. The purpose of this research is to analyze the reform of entrepreneurship education in the fusion of industrial education and university education and use the latest $5 \mathrm{G}$ fog computing technology. In this study, we select different types of universities and graduates as our subject. This study gathers the problems that exist in the academic view and measures of the integration of university production and education, education facilities, and entrepreneurship education through research, literature analysis, and interview methods. A corresponding solution is proposed in conjunction with an analysis model of student performance evaluation. The results show that $22 \%$ of teachers think that entrepreneurship education helps students develop in an all-round way, $42 \%$ of teachers interviewed think that entrepreneurship education is "graduation service," $13 \%$ of teachers think that entrepreneurship education is an organic supplement to professional education, and $23 \%$ of teachers interviewed say it is difficult to position it. $80.5 \%$ of university teachers think that the current school management system is not suitable for combination of production and learning, school enterprise cooperation, and development needs. It is concluded that the reform of entrepreneurship education system industry and education that are combined in this study has a good effect on improving the current employment problem, but the adaptation degree of colleges and universities is insufficient. This study contributes to the development of integrated model of new technology with entrepreneurship education.
\end{abstract}

\section{Introduction}

In the process of deepening entrepreneurship education in various universities, it is very important to cultivate largescale entrepreneurship and innovation. However, as a new product of the times, there are many problems in entrepreneurship education. For example, the positioning of entrepreneurship education is vague. This is determined by the current situation of education in our country and the social background. In order to manage innovation and entrepreneurship, some local universities have joined the
Youth League Committee as ideological and political work. For qualified teachers, the relevant courses are basically not part-time jobs of full-time teachers. Entrepreneurship education lacks profound development from recognition to action. These problems can be said to be accompanied by the disadvantages of practice, which require the optimization and promotion of entrepreneurship education.

5G fog computing is a new technology. In this mode, data, data processing, and applications are concentrated in devices at the edge of the network, instead of all remaining in the cloud. It is a derivative concept of cloud computing, 
which combines the new combining technology with traditional university education, this is very important to demonstrate the functions of the university and to improve social benefits. As far as the educational system is concerned, the main purpose of higher education reform characterized by reform and development is to promote the establishment of vocational education system in contemporary China, to realize the classification and management of universities, to improve higher education, and to educate the national economy.

In the research of entrepreneurship education and industry education integration, Zhang analyzed on the combination of production and learning, school enterprise cooperation, and the necessity of application-oriented personnel training mode. He summarized the innovation direction of application-oriented talent training mode, analyzed the characteristics of facility agricultural science, combined with engineering specialty, and discussed the related knowledge of facility agriculture teaching reform under the applied talent training mode of "combination of production and education, school enterprise cooperation." His method is out of date and inefficient [1]. Based on the spiral theory of three elements, Zizhou analyzes the functions of universities, enterprises, and government, namely, cultural function, economic function, and political function. His research focuses on promoting the development of regional innovation through the integration of industry, university, and research, making the three independent and complementary, forming a regional innovation network. His method is not practical [2]. Bullough et al. propose a framework for designing and implementing effective programs for women based on rich first-hand experience in entrepreneurship education and training programs and a comprehensive review of entrepreneurship and leadership literature related to entrepreneurship education and training. His framework provides the core factors that need to be considered to effectively achieve project goals: project elements, human factors, environment, and funding. Although his framework is generally applicable to entrepreneurial education and training projects, he has demonstrated its effectiveness by sharing first-hand examples with more than 20 female entrepreneurs in developing countries in the past 10 years. His method provides guidance to project managers who study entrepreneurship, leadership, business, and women in developing economies and provide entrepreneurial education and training programs. His method is not accurate enough [3]. Mandell's study analyzes the experimental entrepreneurship education programs in the top 25 undergraduate schools in the US. He is aware of the diversity and dynamism of entrepreneurship experienced in the United States. One of his goals is to investigate barriers to experienced entrepreneurship and determine affordable and viable options. He investigated the Dean of the School, the Rector, and the Undergraduate Project Director and evaluated and analyzed the experience gained from hightech business creation projects. His research was aimed at entrepreneurship education researchers and business project managers, and his methods are not working [4].
The study first presents the basic elements of integration into production education, then six main characteristics of the integrated entrepreneurship education system. The study also describes concrete ways of promoting the development of entrepreneurship and use the latest $5 \mathrm{G}$ fog computing calculation to conduct in-depth research on the subject of this article. The main algorithms of the present study are the factor analysis models and $Z$ standard fractions for the assessment of student performance. This study selected the different types of higher education institutions and of graduates from our province as a subject of study and carried out an experimental analysis of the reform of entrepreneurship education linked to productive education. Combining the results of the experiment with an analysis of the main problems is related to the integration of industrial research, to the practical orientation and reform of the teaching of innovative entrepreneurship, and to the integration of the teaching of innovative entrepreneurship and industrial research. The results of quantitative assessments are analyzed. The conclusion of this study is that the new educational reform may solve the current employment problems of some students.

\subsection{G Fog Computing and Entrepreneurship Education Production Teaching Reform}

2.1.5G Fog Calculation. Fog computing is a newly proposed conceptual model in which data, data processing, and applications are concentrated in devices at the edge of the network instead of almost all stored data in the cloud. It is an extended concept of cloud computing. The concept of fog computing technology was proposed in 2011 and was defined in detail in 2012. Just like cloud computing, fog computing is also very vividly defined. "The cloud is high in the sky, very abstract, while the fog is close to the ground, with you and me." Fog computing does not have strong computing power, only some weak, scattered computing devices. Fog computing is not composed of powerful servers but is composed of computers with weaker and more scattered functions, which penetrates factories, automobiles, electrical appliances, street lights, and various supplies in people's material life. It mainly uses devices in the edge network, and data transmission has extremely low latency. Fog computing has a vast geographical distribution and a large-scale sensor network with a large number of network nodes. Fog computing is an extension of the concept of cloud computing. It mainly uses devices in the edge network, and data transmission has extremely low latency. Fog computing has a vast geographical distribution and a largescale sensor network with a large number of network nodes. Fog computing has good mobility, mobile phones, and other mobile devices can communicate directly with each other, and the signal does not need to go to the cloud or even the base station to go around, supporting high mobility. Fog computing is not a powerful server, but is composed of computers with weaker and more dispersed functions. Fog computing is between cloud computing and personal computing and is a paravirtualized service computing architecture model. Emphasizing quantity, no matter how 
weak a single computing node is, it must play a role. Compared with cloud computing, the architecture adopted by fog computing is more distributed and closer to the edge of the network. Fog computing concentrates data, data processing, and applications in devices at the edge of the network, instead of storing almost all of them in the cloud like cloud computing, data storage, and processing rely more on local devices rather than servers. Fog computing is a new generation of distributed computing, in line with the "decentralized" characteristics of the Internet. Decentralization is the form of social relations and content generation formed during the development of the Internet and is a new type of network content production process relative to "centralization." Decentralization is not about avoiding the center, but letting nodes freely choose the center and freely determine the center. Simply put, centralization means that the center determines the node. The node must rely on the center, and the node cannot survive if it leaves the center. In a decentralized system, anyone is a node, and anyone can become a center. No center is permanent, but phased. No center is mandatory for nodes. Fog computing is completely different from cloud computing. Cloud computing is based on the services of IT operators and social public clouds. Fog computing wins by quantity, emphasizes quantity, and plays a role no matter how weak a single computing node is. Cloud computing emphasizes overall computing power, and calculations are generally completed by a bunch of concentrated high-performance computing devices. Fog computing expands the network computing model of cloud computing, extends network computing from the network center to the network edge, and thus is more widely used in various services. The country is vigorously developing the Internet of Things. The final result of the development of the Internet of Things is to interconnect all electronic devices, mobile terminals, household appliances, and so on. These devices are not only huge in number but also widely distributed. Only fog computing can satisfy the reality. Demand puts forward requirements for fog computing and also provides development opportunities for fog computing.

Cloud computing (cloud computing) technology is a type of distributed computing, which refers to the decomposition of huge data computing processing programs into countless small programs through the network "cloud," and then processing and analysis through a system are composed of multiple servers. These small programs get the results and return them to the user. "Cloud" is essentially a network. In a narrow sense, cloud computing is a network that provides resources. Users can obtain resources on the "cloud" at any time, use them as needed, and can be regarded as unlimited expansion, as long as you can pay for what you use. The "cloud" is like a water plant. We can receive water at any time and there is no limit. You can pay the water plant according to your own water consumption. Tracing back to the root of cloud computing, its emergence and development are closely related to the aforementioned parallel computing, distributed computing, and other computer technologies, which promote the growth of cloud computing. Virtualization technology must be emphasized that virtualization breaks through the boundaries of time and space and is the most significant feature of cloud computing. Virtualization technology includes application virtualization and resource virtualization. As we all know, there is no spatial connection between the physical platform and the application deployment environment, and it is through the virtual platform to complete the data backup, migration, and expansion of the corresponding terminal operations.

\subsection{Basic Connotation of Industry Education Integration.} Carrying out school-enterprise cooperation is an important part of the professional construction of vocational colleges and an important way for vocational colleges to demonstrate their school-running characteristics and improve teaching quality. The order-based talent training model is based on the three parties of schools, students, and enterprises. A cooperative school-running model established between schools and enterprises is based on cultivating student abilities and enterprise development. The unity of production and education is to realize the unity of production and education through the interaction between schools and enterprises. The detailed relationship between corporate production and education is combined with college education, higher education, corporate production, student quality improvement, scientific research and development, social services, and corporate management. The concept of combination of industry and education is to deepen the separation of education and employment, work, and learning, organically organise universities and businesses, form benign interactions and common development, and achieve the ideal benefits for each. The concept of industrial and educational combination is the combination of higher education and training skills and the need for quality employee training, changes between universities and businesses, and domestic industry. The advancement and innovation of traditional industries and technological progress in the enterprise have played an exciting role $[5,6]$.

\subsection{Characteristics of the Integrated Entrepreneurship Education Curriculum System}

2.3.1. Diversity. Diversity refers to the construction of each component of the curriculum system in a variety of forms, including the comprehensive consideration of each link, the diversity of target elements, the diversity of content elements, and the realization of good. The characteristics of interdisciplinary and interdisciplinary, for example, the goal elements must include the cultivation of entrepreneur consciousness, entrepreneur spirit quality, entrepreneur knowledge, entrepreneur ability, and so on. Elicitors must include entrepreneurial elements. Courses, basic knowledge courses of entrepreneurship, comprehensive courses of experts, entrepreneurship practice courses, other types of courses, various courses, and various talent training objectives are the key points [7].

2.3.2. Practicality. The course system remains a fundamental and important part of entrepreneurship education; therefore, the education system remains operational. 
Entrepreneurship is an important factor for success in business. Entrepreneurship learning should build on the experience of entrepreneurship, so practice is one of the fundamental characteristics of a comprehensive entrepreneurship training program $[8,9]$.

2.3.3. School Wide. The basic principle of integrated entrepreneurship education curriculum system is to face the whole school. Teachers and other resources are provided by business schools to form a self-sufficient curriculum pattern. The merged curriculum system of entrepreneurship education breaks the boundary of focusing mode. The target of education will be extended to the whole school, integrating various resources of the government, society, and the school, so that college students of all majors have the opportunity to receive entrepreneurship education $[10,11]$.

2.3.4. Difference. Comprehensive entrepreneurship education curriculum system should not only focus on the construction of the whole school but also fully respect the independent choice of college students, that is, to reflect different characteristics. However, from an objective scientific point of view, not all college students want to train entrepreneurs and entrepreneurs. In order to become such a person, they are generally cultivating the awareness and spirit of entrepreneurs, on the basis of interest and enthusiasm of college students to realize the dream of entrepreneurs. Second, due to the different knowledge structure of different majors, the construction of curriculum system cannot ignore the difference of experts [12].

2.3.5. Continuity. The comprehensive entrepreneur education curriculum system fully considers the individual differences of college students, so the curriculum system is a continuous education process composed of multiple education stages, from shallow to deep, from popular to difficult, and from basic to professional experience. Moreover, the merged entrepreneur education curriculum system cannot be constructed without the basic principles of education and the basic laws of college students' personal development.

2.3.6. Innovation. Entrepreneurship education has a strong social character and is very sensitive to social, political, and economic development and change. Innovation is the life and soul of entrepreneurs. The merged entrepreneur education curriculum system must also recognize the importance of entrepreneurship innovation. Therefore, the various subsystems that constitute the curriculum system are always implemented and learning fields of professional knowledge such as the use of professional knowledge, the development of creative resources, the integration of resources, and the use of resources $[13,14]$. Figure 1 shows the characteristics of the curriculum system of the integration of industry and education.

\subsection{Specific Ways to Promote the Formulation of Laws and Regulations on the Integration of Industry and Education}

2.4.1. Accelerating the Establishment of Domestic Restrictions. The combination of industry and education mainly uses various cooperation methods of universities, enterprises, and scientific research institutions. Because scientific research and technology cannot meet the requirements of enterprises, the method of "cooperative science education" implemented by education university aims at cultivating applied talents with innovative ability and high technology. On the basis of resource sharing, it cannot be mutually beneficial. Without the national macro policy and legal guarantee, all the beautiful "cooperative science and education" methods will not develop for a long time $[15,16]$.

2.4.2. Improving Industry and Regional Rules and Regulations. We should encourage the government to participate in the formulation of policies, regulations, and industry management. Through the use of laws, regulations, laws, and regulations, further restrict the rights and obligations of the government, enterprises, and industries and cultivate application-oriented talents in the integration of industries and education. In particular, the industries and enterprises that take part in the combination of industry and education determine the nature and status of applied talents participating in training. Specific provisions provide assurance of policies and regulations $[17,18]$.

2.4.3. Special Regulations on Promoting Education. The rights and obligations of the parties clearly define the rights and obligations of integration, the management modes, and the talent for industry and education $[19,20]$. The training mode and the use of funds, the mechanisms of corresponding remuneration and punishment, and the government's liability and legal liability are very important. We need to establish a unified educational system. The characteristics of modern corporate talent development should be the establishment of a modern corporate education system, radiation exposure to a full employment access system, changing the current state of existing employment access systems, and establishing employment-level standards to improve employment access systems [21].

2.5. Factor Analysis Model of Student Achievement Evaluation. The model here is multiple and difficult to understand, but the problem is not big. I use many algorithms to describe this model in terms of algorithms, to show the accuracy of the analysis model.

2.5.1. Factor Analysis. Analysis techniques include regression analysis, causal analysis, grouping method, root cause analysis, prediction method (time series/scenario construction/simulation, etc.), failure mode and effect analysis (FMEZ), fault tree analysis, reserve analysis, trend analysis, earning value management, and difference analysis. Factor collection technology refers to the use of computer software 


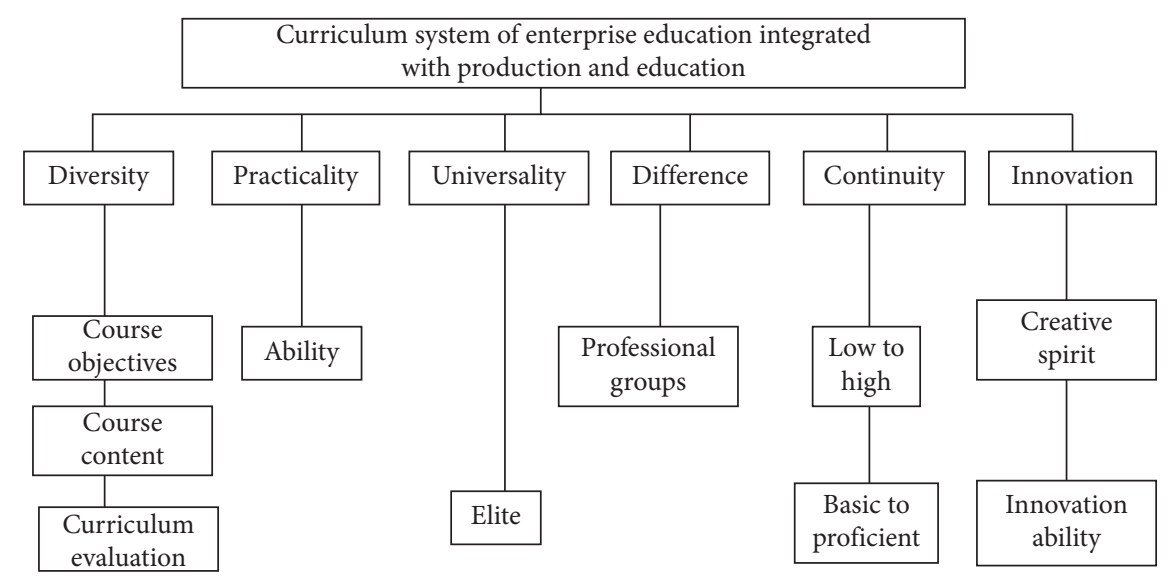

FIGURE 1: Characteristics of the curriculum system of enterprise education integration.

technology to conduct real-time information collection, extraction, mining, and processing for customized target data sources; extract unstructured information from a large number of web pages and save it in a structured database; and provide the entire process of data input for various information service systems.

The calculation steps of factor analysis are as follows:

(1) Raw data have been standardized to eliminate size order variables and size differences [22].

(2) Correlation matrix requirements to obtain standardized data.

(3) Determine the factors; let $f_{1}, f_{2}, f_{3}, \ldots, f_{p}$ be $p$ factors, in which the total amount of information contained in the first $C$ factors, that is, when the cumulative contribution rate mentioned above exceeds $80 \%$, we can extract the first $C$ factors to reflect the overall situation and reflect the original data.

(4) It is impossible to judge that the cumulative contribution rate of the extracted factor $C$ is less than $80 \%$, and the actual meaning of the formula cannot be determined, so it is necessary to transfer the fax.

(5) A linear combination of raw data variables to get points for each factor. Factor scores can be used for calculation: regression estimation and Thomson estimation $[23,24]$ :

$$
F=\frac{\left(\lambda_{1} f_{1}+\lambda_{2} f_{2}+\lambda_{3} f_{3}+\cdots+\lambda_{p} f_{p}\right)}{\lambda_{1}+\lambda_{2}+\lambda_{3}+\cdots+\lambda_{p}},
$$

where $\lambda_{i}$ is the variance contribution rate of factors.

(6) Results ranking: the overall score is used to obtain the ranking list, which can be compared with the original data [25].

2.5.2. Mathematical Model of Factor Analysis. The factor analysis model is as follows: $M$ original variables are $x_{1}, x_{2}, x_{3}, \ldots, x_{m}$. To find $P$ factors $(P<m)$ as $f_{1}, f_{2}, f_{3}, \ldots, f_{p}$, the relationship between principal components and original variables is expressed as follows:

$$
\begin{aligned}
& x_{1}=\partial_{11} f_{1}+\partial_{12} f_{2}+\partial_{13} f_{3}+\cdots+\partial_{1 p} f_{p}+\theta_{1}, \\
& x_{2}=\partial_{21} f_{1}+\partial_{22} f_{2}+\partial_{23} f_{3}+\cdots+\partial_{2 p} f_{p}+\theta_{2}, \\
& \cdots \\
& x_{m}=\partial_{m 1} f_{1}+\partial_{m 2} f_{2}+\partial_{m 3} f_{3}+\cdots+\partial_{m p} f_{p}+\theta_{m} .
\end{aligned}
$$

The coefficient $\partial_{i j}$ is the relationship between the $i$ th variable and the $P$ variable. A coefficient represents a linear combination of the original variable and a coefficient also known as a common coefficient. $\theta$ is a special factor and an influential factor other than the common one. The earlier equation can be described in matrix form as follows:

$$
X=K F+\theta .
$$

$F=\left(f_{1}, f_{2}, f_{3}, \ldots, f_{p}\right)^{T}$ is the common factor vector, that is, the main factor, $\theta=\left(\theta_{1}, \theta_{2}, \theta_{3}, \ldots, \theta_{m}\right)^{T}$ is the special vector factor, and $K=\left(\partial_{i j}\right)_{m \times p}$ is the factor load matrix.

$$
\begin{aligned}
E(F) & =0, \\
\operatorname{var}(F) & =I_{p}, \\
E(\theta) & =0, \\
\operatorname{var}(\theta) & =D=\operatorname{diag}\left(\varepsilon_{1}^{2}, \varepsilon_{2}^{2}, \varepsilon_{3}^{2}, \ldots, \varepsilon_{m}^{2}\right), \\
\operatorname{cov}(F, \theta) & =0 .
\end{aligned}
$$

Based on the above assumptions, we clearly know that there is no relationship between common factors, there is a square identity matrix, there is no relationship between special factors, and there is no relationship between special factors and common factors.

Common measurement is

$$
Z_{i}^{2}=\sum_{j=1}^{m} \partial_{i j}^{2}, \quad i=1,2, \ldots, p .
$$

The degree to which the information of variable $x_{i}$ can be explained by $P$ common factors is expressed by the variance 
contribution rate of $P$ common factors to $x_{i}$ I. Contribution rate of factor variance is

$$
H_{j}^{2}=\sum_{i=1}^{p} \partial_{i j}^{2}, \quad j=1,2, \ldots, m .
$$

The variance sum of the $j$ th common factor to variable $x_{i}$ reflects the relative importance. In the factor analysis of students' scores, $X=\left(X_{1}, X_{2}, X_{3}, \ldots, X_{n}\right)^{T}$ can represent the $m$-dimensional random variable composed of $n$ students' $m$-subject scores, while $F=\left(f_{1}, f_{2}, f_{3}, \ldots, f_{p}\right)^{T}$ cannot represent that $p$-dimensional random vector is a common factor. The actual significance of $F$ still needs to be treated with specific problems.

2.5.3. Establishment Factor of Score Function. This function can be used to quickly establish the scoring function:

$$
\begin{aligned}
F_{1}= & -0.326 X_{1}+0.073 X_{2}-0.390 X_{3}+0.692 X_{4} \\
& +0.407 X_{5}+0.344 X_{6}, \\
F_{1}= & 0.622 X_{1}+0.220 X_{2}+0.700 X_{3}-0.462 X_{4} \\
& -0.130 X_{5}-0.89 X_{6} .
\end{aligned}
$$

From (7), you can calculate each student's fax score for free art and science faxes. The previous series of steps helps to save the new variables "fac1-1" and "fac2-1." Because we want to know more about the students' comprehensive scores after knowing their fax scores, we need to weigh the sum of the scientific factor $F 1$ and the liberal factor $F 2$, and the following equation is obtained:

$$
F=\frac{43.139 \% \times F_{1}+38.056 \% \times F_{2}}{81.195 \%} .
$$

This is the comprehensive evaluation factor of students. According to the expression of the comprehensive evaluation factor, we can rank the students and compare them with the original data.

2.6. Standard Z-Score. The Z-score is also known as the standard score. The standard score formula is as follows:

$$
Z=\frac{X-\theta}{\varepsilon},
$$

where $x$ is the original score of a subject, that is, the specific score, $\theta$ is the average, $\varepsilon$ is the standard deviation, and $X-\theta$ is the deviation from the average.

$$
\begin{aligned}
& \theta=\frac{1}{N} \sum_{i=1}^{N} X_{i}, \\
& \varepsilon=\sqrt{\frac{1}{N} \sum_{i=1}^{N}\left(x_{i}-\theta\right)^{2}}=\sqrt{\frac{1}{N} \sum_{i=1}^{N} X_{i}^{2}-\left(\frac{1}{N} \sum_{i=1}^{N} \theta\right)^{2}} .
\end{aligned}
$$

The calculation method of frequency distribution table is

$$
\theta=\frac{f_{1} X_{1}+f_{2} X_{2}+f_{3} X_{3}+\cdots+f_{m} X_{m}}{f_{1}+f_{2}+f_{3}+\cdots+f_{m}}
$$

where $X_{i}$ represents the group median value of group I and $f_{i}$ represents the frequency of group I.

$$
\varepsilon=\sqrt{\frac{1}{N} \sum_{i=1}^{n} f_{i} X_{i}-\theta^{2}},
$$

where $Z$ is the distance between the original score and the volume average of the matrix. It is calculated according to the standard deviation of the element. Because the $Z$ score can reflect the distance between the score and the class average, you can get a better understanding of where you are now.

\section{Teaching Reform Model Design of the Integration of Production and Education}

3.1. Experimental Data Objects. A total of 296 respondents randomly selected the subjects for science, engineering, economics, business, and other major to advanced subjects. Thirty-three questions were invalid because they were not answered. A total of 263 valid questions were returned, and the actual recovery was $88.85 \%$. The questionnaire is divided into six sides and has 17 questions. In other words, six dimensions are included, such as the intention of entrepreneur education, the development of entrepreneur education, the purpose of the curriculum, the teacher team, curriculum evaluation, and curriculum implementation.

\subsection{Research Methods}

3.2.1. Literature Analysis. The literature analysis method refers to the method that investigates the nature and status of the research object by studying the collected literature data and derives one's own views from it. It can help investigators to form a general impression about the research object, which is conducive to the dynamic grasp of the history of the research object and can also study research objects that are no longer accessible, such as people who have long died. The main content of the literature analysis method is as follows: (1) analyze and research the relevant archive materials found; (2) analyze and research the collected personal diaries, notes, and biographies; and (3) analyze and research the collected publicly published books and periodicals and other materials.

3.2.2. Questionnaire Survey. This study is based on a comprehensive understanding of the relationships between teachers and students in the area of entrepreneurial innovation, relationships with vocational education, teacher strength, educational programs, and practical platforms. The questionnaires were developed on their own initiative and the experts and part-time teachers used a simple method of random sampling. Student questionnaire survey the 
combination between innovation entrepreneurship education and professional education.

3.2.3. Semistructured Interview. In the survey, teachers and students can understand the combination of innovation, entrepreneur education, and professional education from the perspective of the questionnaire. Therefore, in this study, based on the five sides of the questionnaire, we create an interview and select the interview person by the simple random sampling.

3.3. Construction of the University Teaching System under the Guidance of Entrepreneurship Education Concept. In order to foster talented people with entrepreneurship, it is necessary to combine the research objectives of the school with current employment and economic development. The demand for existing professionals and markets is not necessarily the case. Based on the completion of the original training purpose of the technical college, focusing on the growth of expert spirit and entrepreneurship, the target training course provides a multilevel comprehensive content system for quality and capacity of the above and builds the intensity target system. Based on practical educational content, we increase entrepreneurship education and add various entrepreneurial knowledge, entrepreneurial content, and various entrepreneurial content, as well as pay attention to increasing lectures and courses on business operation and management, such as learning and practice in procurement, production, sales, and management systems.

\section{Problems and Measures of Entrepreneurship Education Reform in the Integration of Industry and Education}

\subsection{Main Problems Related to the Integration of Motherhood}

\subsubsection{Construction of the University Management System} Lags Behind. In recent years, the practice of "reform and development" of local universities in China has proved that the existing school-level system has basically retreated. The "reform measures" explored by secondary universities and scientific research institutions and the "existing system" at school level have reached all directions. "Fight" or "run into a brick wall" until many reform measures are difficult to achieve. Table 1 shows the statistics on the types of industry education integration system.

As can be seen from Table 1, more than four-fifths of teachers believe that the school has formulated a comprehensive system of production and education, while about one-fifth of teachers believe that there is no unified system of production and education. Not all teachers are familiar with this system. In addition, only 25 selected education, scientific research, finance, student management, personnel, and other five projects at the same time, accounting for $4.4 \%$ of the 574 valid questionnaires. There are very few newly established universities with unified production and education system. Mainly focus on logistics support and political party issues and other systems, fill in "other" interviewees.
Table 2 shows the adaptation of school teaching management system and industrial research.

As shown in Table 2, the new undergraduate schools in China are establishing an integrated special education system; however, there is no support system in the fields of scientific research, finance, personnel, etc., of the integration of industrial research and cooperation between enterprises. Management system as to whether the system meets the requirements of productive integration and cooperative development, the $80.5 \%$ of secondary school teachers believe that the current teaching management system for the integration of production and education is "unsuitable" or "unsuitable" for codevelopment needs.

\subsubsection{Legislation on the Integration of Production and Ed-} ucation Is Slow. In the process of merging industry and education, laws and regulations are insufficient. Due to the delay in the formulation of the legal provisions on the merger of industry and education, the legal responsibilities and rights of participants are irregular and cannot be obeyed. As shown in Table 3, main issues are related to the integration of industrial research in the different types of higher education institutions.

As shown in Figure 2, production education is integrated into higher education institutions.

The data shown in Table 3 and Figure 2 show that universities face many problems in integrating industry and education, such as lack of policy and regulatory support, lack of equipment investment, immature external environment, faced by universities in integrating industry and education. But the most significant problems are as follows: lack of support of the law; in general undergraduate colleges, $58.32 \%$ of them lack the support of laws and regulations, which is the most urgent problem among all the problems. At present, we have developed and implemented many policies for integrating research and development in the field of production, but they are neither perfect nor perfect. Industry, cooperation, and planning between universities and businesses are based mainly on verbal agreements rather than informal contracts. If either party violates the contract when tearing up the contract, it cannot rely on relevant policies, laws, and regulations to judge the correctness of the problem, and the oral agreement between the two parties is invalid.

4.1.3. Insufficient Investment. In my country, investments in research and development are increasing, but the rapid growth of GDP is far from sufficient. At the same time, it also developed the unified development of university industry and education in China. This is a very obvious gap and important obstacle as the ratio of R\&D in GDP is very low. The ratio of R\&D to GDP is very low. There is a serious shortage of funds for the integrated development of industrial education. Universities and enterprises cannot be guaranteed with funds, and the integrated development of industrial education is difficult. Table 4 shows China's $\mathrm{R} \& \mathrm{D}$ expenditure and the ratio of $\mathrm{R} \& \mathrm{D}$ to GDP in 2010-2019. 
TABLE 1: Statistics on types of the industry education integration system.

\begin{tabular}{|c|c|c|c|c|c|c|}
\hline System type & Teaching & Scientific research & Finance & Student management & Personnel matters & Other \\
\hline Number & 481 & 109 & 50 & 113 & 80 & 19 \\
\hline Percentage & 83.7 & 19.0 & 8.6 & 19.6 & 13.9 & 3.2 \\
\hline
\end{tabular}

TABle 2: The adaptability of the teaching system to the integration of production and education.

\begin{tabular}{lccccc}
\hline & Very adaptable & Adaptable & More adaptable & Not very adaptable & Maladjusted \\
\hline Number & 22 & 36 & 57 & 378 & 86 \\
Percentage & 3.7 & 6.2 & 9.9 & 65.8 & 14.9 \\
\hline
\end{tabular}

TABLE 3: Main issues related to the integration of industrial research in universities.

\begin{tabular}{lcccc}
\hline Main problems & All universities (\%) & Research universities (\%) & Teaching universities (\%) & Vocational schools (\%) \\
\hline Regulatory support & 60.58 & 47.07 & 58.33 & 76.33 \\
Capital investment & 60.11 & 50.99 & 41.69 & 61.19 \\
External environment & 52.08 & 45.11 & 50.09 & 63.17 \\
Organizational guarantee & 48.52 & 50.99 & 46.23 & 53.96 \\
Coordinating body & 20.35 & 11.77 & 21.02 & 21.72 \\
Service sector & 20.35 & 29.42 & 19.67 & 18.43 \\
Other & 2.65 & 0.00 & 2.87 & 3.30 \\
\hline
\end{tabular}

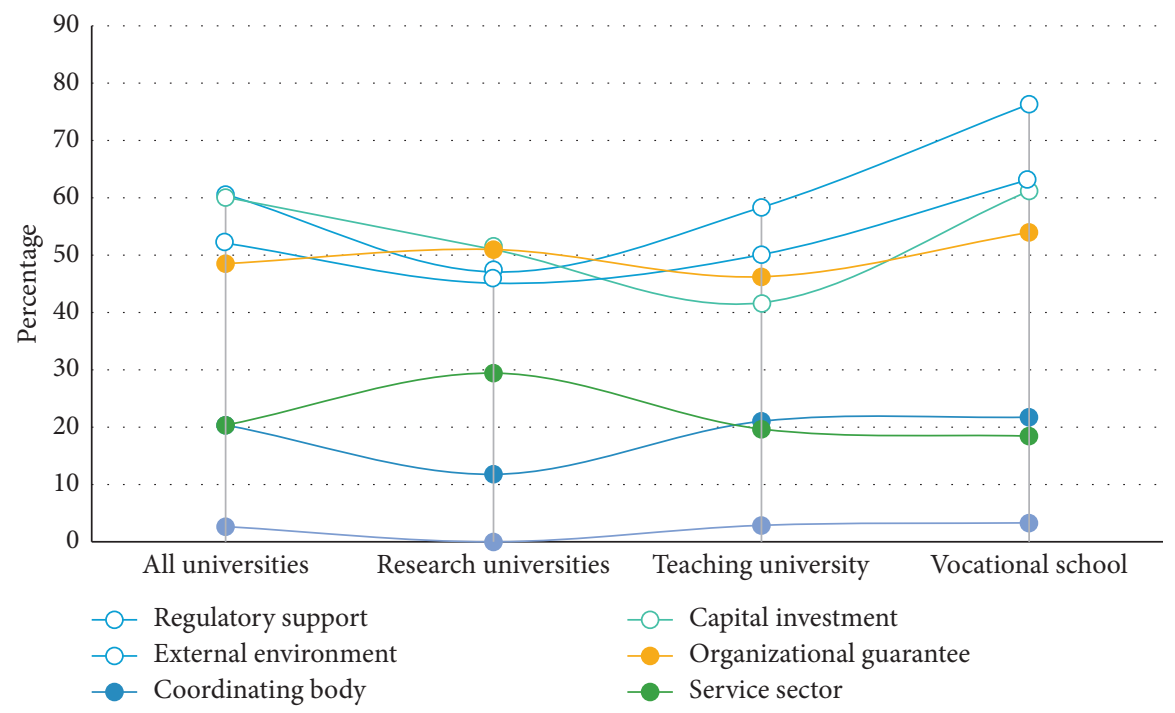

FIGURE 2: Integration of research and production in universities.

TABLE 4: Ratio of R\&D expenditure and R\&D to GDP in 2010-2019.

\begin{tabular}{lcc}
\hline Particular year & Internal R\&D expenditure/100 million yuan & Ratio of R\&D to GDP (\%) \\
\hline 2010 & 2449.98 & 1.35 \\
2011 & 3003.11 & 1.43 \\
2012 & 3710.25 & 1.45 \\
2013 & 4616.03 & 1.55 \\
2014 & 5802.12 & 1.71 \\
2015 & 7062.59 & 1.77 \\
2016 & 8687.02 & 1.85 \\
2017 & 10241 & 1.99 \\
2018 & 11848 & 2.09 \\
2019 & 13401 & 2.11 \\
\hline
\end{tabular}




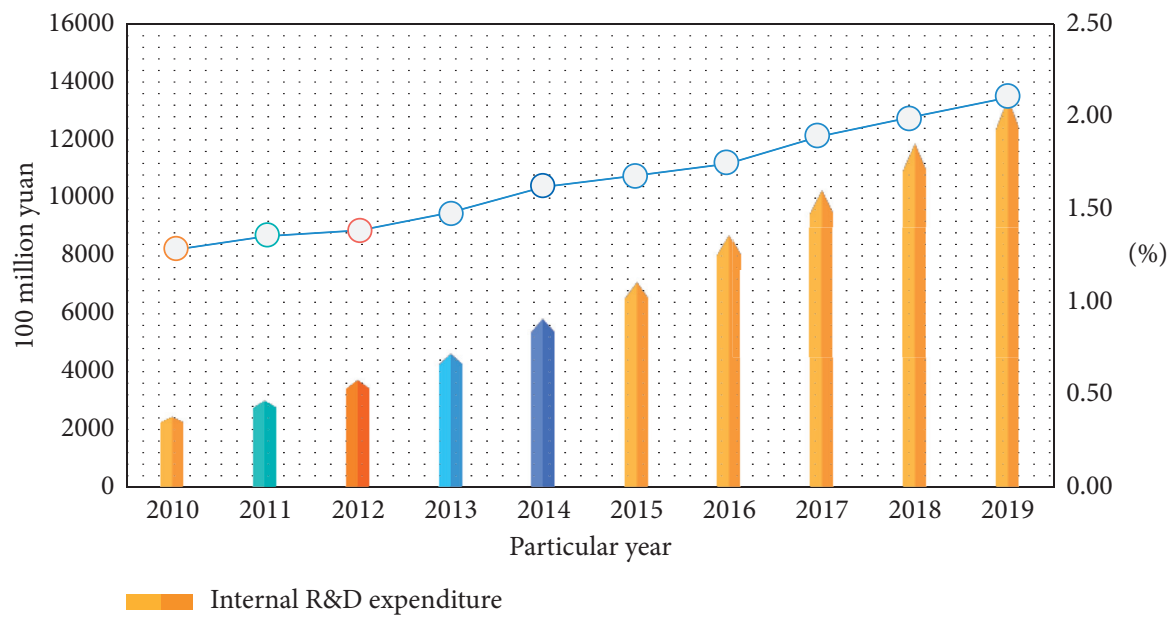

Figure 3: R\&D expenditure and R\&D\% of GDP.

Figure 3 shows China's R\&D expenditure and the percentage of R\&D in GDP in recent years.

As shown in Table 4 and Figure 3, the state lacks financial support for the integration of industry and education. Therefore, it is difficult to balance the interests of enterprises and universities. Because of the liberation of research funds and development costs, expectations are quite different, and the desire of universities and research institutions to apply becomes lower. There is no guarantee that participants will be involved.

4.2. Practice Orientation and Teaching Reform. Education for entrepreneurship is relatively vague. Totally, $43 \%$ of students view entrepreneurial innovation as an "end of study activity" in higher education institutions. Thirty-one percent of students surveyed view innovation as a "student." Type of work; a few respondents (19\%) felt that teaching entrepreneurship was complementary to vocational education. Seven percent of respondents considered education for innovative entrepreneurship to be an ideological and political activity. Statistics of student practice in teaching innovative entrepreneurship are shown in Figure 4.

Analysis of the questionnaires sent to teachers shows that $22 \%$ of teachers consider education for entrepreneurship to be an important element in the overall development of students, $42 \%$ consider education for innovative entrepreneurship as a "service." Thirteen\% of teachers consider that entrepreneurial innovation is an "end of studies service." "I believe that the education of God is an organic complement to professional education." Twenty-three of one hundred teachers surveyed indicated that they were very happy to have trouble finding it. Statistics on the practice of teachers in teaching innovative entrepreneurship are shown in Figure 5.

Figures 4 and 5 reveal an ambiguity in the implementation of innovative entrepreneurship education from a

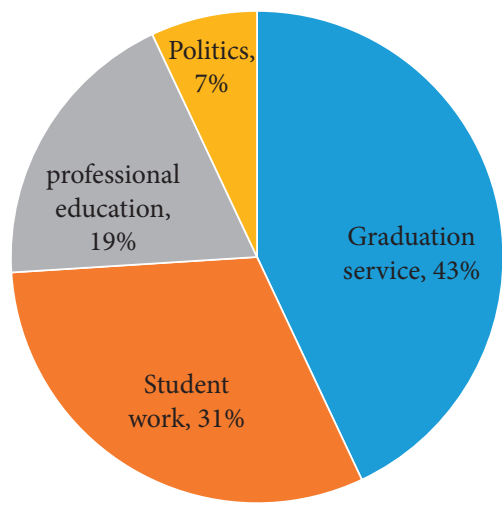

FIgURE 4: Statistics of students' practice on entrepreneurship education.

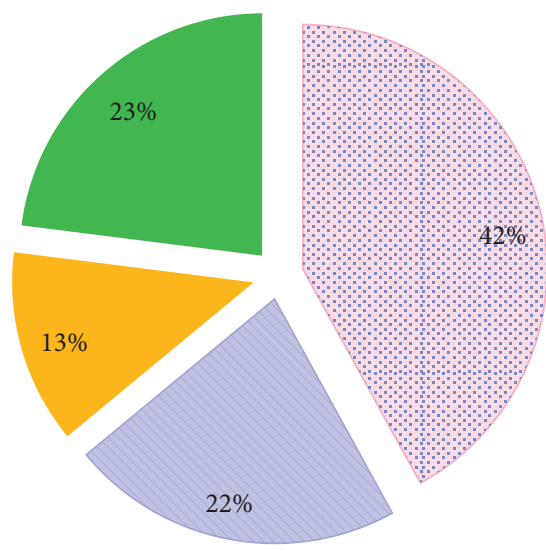

Graduation service

- Student development

- Educational Supplement

- Difficult to locate

FIgURE 5: Statistics of teachers' practice on innovation and entrepreneurship education. 
TABLE 5: Forms of innovation and entrepreneurship education expected by teachers and students.

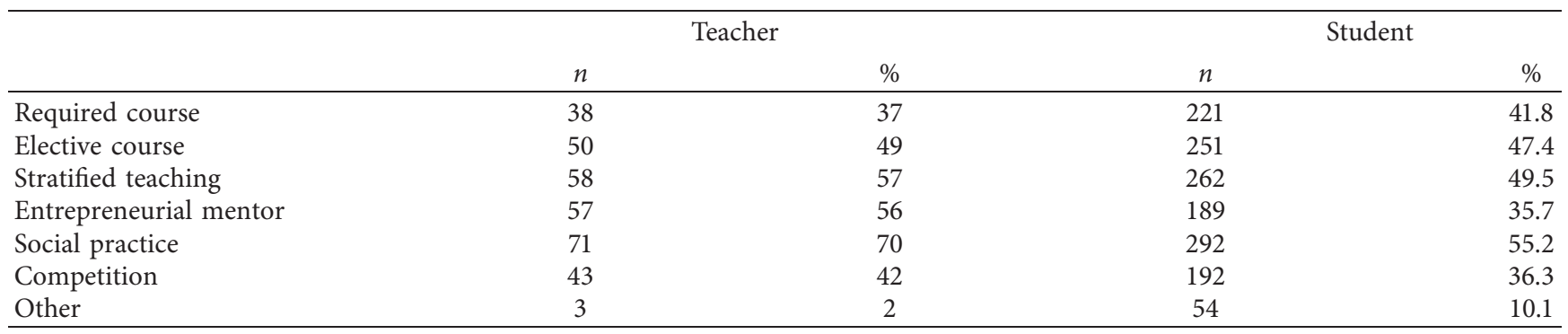

TABLE 6: Opinion of teachers and students on entrepreneurship education program.

\begin{tabular}{|c|c|c|c|c|}
\hline & \multicolumn{2}{|c|}{ Teacher } & \multicolumn{2}{|c|}{ Student } \\
\hline & $n$ & $\%$ & $n$ & $\%$ \\
\hline Business orientation & 76 & 75 & 396 & 74.9 \\
\hline Management & 50 & 49 & 285 & 53.9 \\
\hline Practical learning & 72 & 71 & 371 & 70.2 \\
\hline Professional theory & 48 & 47 & 282 & 53.3 \\
\hline Operational capability & 66 & 65 & 335 & 63.4 \\
\hline Social experience & 56 & 55 & 328 & 62.0 \\
\hline Other & 10 & 10 & 64 & 12.0 \\
\hline
\end{tabular}

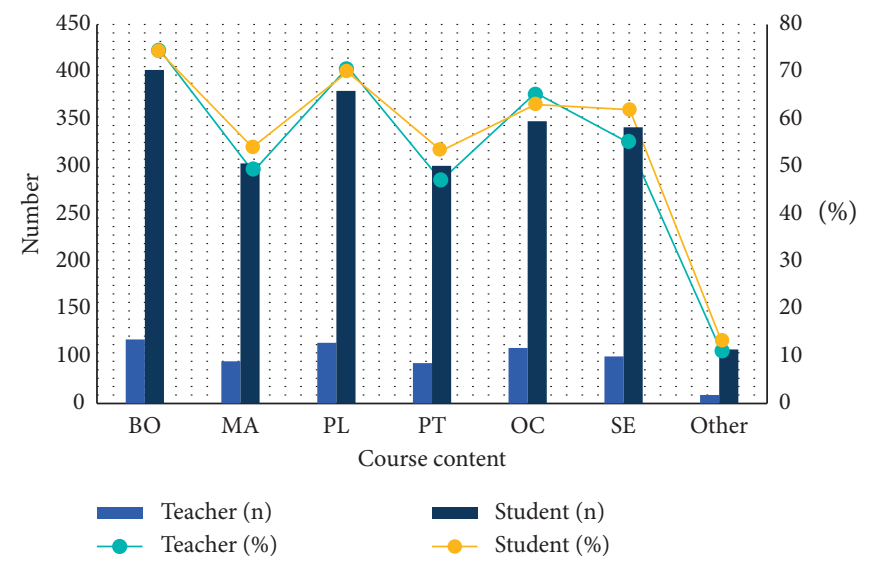

FIGURE 6: Curriculum content of innovation and entrepreneurship education.

higher education perspective. It is clear that innovative entrepreneurship education is not effective. However, the relationships between educational specialists, innovators, and educators have been neglected.

\subsection{Innovation and Entrepreneurship Education and Industry Education Integration}

(1) According to the survey results, most teachers and students believe that innovative entrepreneurship education programs should take the form of social practices. Most educational activities focus on teaching knowledge due to the traditional conception of education, local universities provide practical resources to students, and development of practical and practical skills of students requires appropriate practical skills and abilities. As shown in Table 5, teachers and students expect innovative education programs on entrepreneurship.

(2) Most teachers and students want to learn about entrepreneurship choice as part of entrepreneurship education programs, and when it comes to employment challenges, students want to better understand the spirit of entrepreneurship. Learning to innovate in entrepreneurship and laying the groundwork for future teacher and student views of entrepreneurship education programs, as shown in Table 6.

Figure 6 shows the content of entrepreneurship education courses for teachers and students.

As shown in Figure 6, although efforts are being made to integrate the current curriculum, it is not very focused; most of the courses are based on basic concepts and skills in entrepreneurship. 


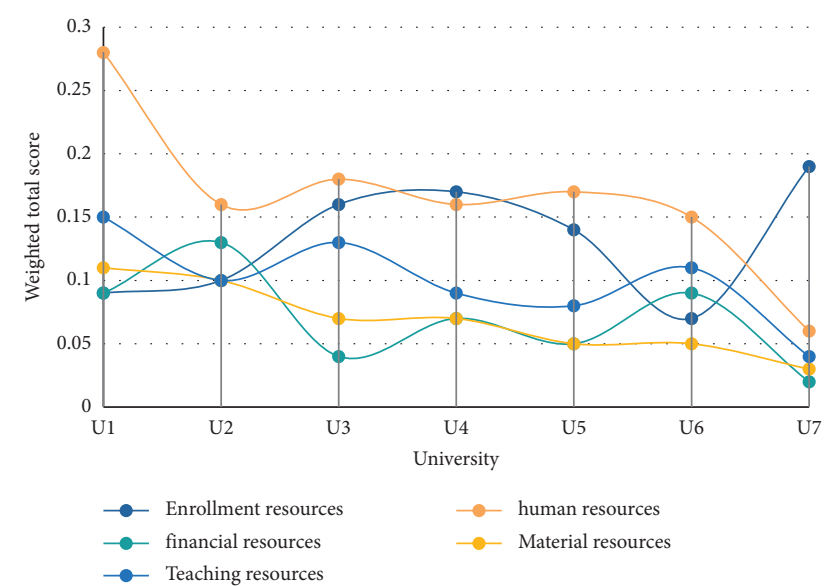

Figure 7: The result of quantitative evaluation of resource allocation of industry education integration in colleges and universities.

4.4. Quantitative Evaluation Results. By calculating the weight of the index, the size of the indicator system and the weight of each index are obtained. The standard value after the original data of the index is converted is weighted. After calculating the index scores of the two stages, the general situation is obtained for the quantitative evaluation score and ranking of educational resource allocation. The quantitative evaluation results of the allocation of integrated education resources of university production and education are shown in Figure 7.

As can be seen from Figure 7, universities in our province have the overall strongest advantage in the allocation of educational resources for education majors, ranking first in human resources, financial resources, material resources, and educational resources. The results of the quantitative evaluation of the allocation of professional education resources are in line with the assumption that the results of the quantitative evaluation of the allocation of educational resources of two or three new universities are relatively low.

\section{Conclusion}

The integration of research and development in the field of production is essential to meet the needs of social development and to adapt educational resources and social objectives. I know how to make a comprehensive evaluation of the above four industrial structures, the guarantee and guarantee of enterprise development, and the basic system of enterprise development and also understand how to establish a series of standardized standards and standardized cooperative relations to support the unified management system of university production and education. 5G fog computing is now a hot new technology. With the vigorous development of the Internet of Things, Big Data, 5G, and other technologies, various devices have begun to be interconnected. A large number of devices are not only numerous but also widely distributed. Only fog computing is required in order to meet its requirements. The combination of fog computing and entrepreneurial education in colleges and universities can allow students to understand the current hot technologies and development directions, which is very educational.

Through interviews and questionnaires with more than 800 graduates and graduate graduates, this study shows that teaching entrepreneurship in higher education institutions is poorly developed and students are poorly motivated. The theoretical path system of innovation entrepreneurship in college and education pattern is not flexible. School policies are not sufficiently supported, and there is no favorable climate for innovative entrepreneurship.

Our entrepreneurship education can neither blindly promote the "doctrine of usage" nor blindly imitate it. However, we should deepen the integration of the latest technologies such as $5 \mathrm{G}$ fog computing with entrepreneurship education and explore the entrepreneurship education with Chinese characteristics from those experiences in the integration of industry and education.

\section{Data Availability}

The data that support the findings of this study are available from the corresponding author upon reasonable request.

\section{Conflicts of Interest}

The authors declare no conflicts of interest with respect to the research, authorship, and/or publication of this article.

\section{Acknowledgments}

This work was supported by Social Sciences Research Project of Hubei Provincial Education Department in 2020 (project title: High-quality Development of Sports Industry in $\mathrm{Na}-$ tional Central Cities, Contract No. 20D052), supported by Social Science Foundation of Wuhan Institute of Technology and Teaching Research of Wuhan Institute of Technology in 2020 (project title: The Practice of Innovation and Entrepreneurship Talent Cultivation Innovative Model for Sports Graduate Students Based on the Integration of Education, Industry and Research), and 2019-2020 Education Research of Wuhan Institute of Technology (project title: Research on the Cultivation Effect of Interdisciplinary Talents in Sports Economics and Management, Contract No. 2020YB13).

\section{References}

[1] Y. Zhang, "Preliminary study on teaching reform of facility agriculture specialty under the model of "industry-education integration and school-enterprise cooperation," International Journal of Social ence and Education Research, vol. 2, no. 12, pp. 64-69, 2020.

[2] Y. Zizhou, "The main function of the integration of the production and education in the perspective of triple spiral," Special Zone Economy, vol. 12, no. 1, pp. 31-37, 2016.

[3] A. Bullough, M. S. De Luque, D. Abdelzaher, and W. Heim, "Developing women leaders through entrepreneurship education and training," Academy of Management Perspectives, vol. 29, no. 2, pp. 250-270, 2016. 
[4] R. Mandel and E. Noyes, "Survey of experiential entrepreneurship education offerings among top undergraduate entrepreneurship programs," Education + Training, vol. 58, no. 2, pp. 164-178, 2016.

[5] J. Radloff, "Elementary teachers' positive and practical risktaking when teaching science through engineering design," Journal of Pre-College Engineering Education Research (J-PEER), vol. 9, no. 2, p. 4, 2019.

[6] Y. Zhou, K. Su, and L. Shao, "Reform and exploration of virtual experiment teaching in the course of modern control system," Agro Food Industry Hi-Tech, vol. 28, no. 1, pp. 1904-1908, 2017.

[7] W. Yi and X. Wei, "Suggestions and countermeasures of integration of production and education in higher vocational colleges," International Journal of Software Engineering and its Applications, vol. 11, no. 5, pp. 109-114, 2017.

[8] L. Pittaway and J. Cope, "Entrepreneurship education," International Small Business Journal: Researching Entrepreneurship, vol. 25, no. 5, pp. 479-510, 2016.

[9] A. D. Daniel, "Fostering an entrepreneurial mindset by using a design thinking approach in entrepreneurship education," Industry and Higher Education, vol. 30, no. 3, pp. 215-223, 2016.

[10] S. G. Walter and J. H. Block, "Outcomes of entrepreneurship education: an institutional perspective," Journal of Business Venturing, vol. 31, no. 2, pp. 216-233, 2016.

[11] M. Entrialgo and V. Iglesias, "The moderating role of entrepreneurship education on the antecedents of entrepreneurial intention," The International Entrepreneurship and Management Journal, vol. 12, no. 4, pp. 1209-1232, 2016.

[12] V. B. Sánchez and C. A. Sahuquillo, "Entrepreneurial intention among engineering students: the role of entrepreneurship education," European Research on Management \& Business Economics, vol. 24, no. 3, pp. 53-61, 2018.

[13] A. Fayolle, C. Verzat, and R. Wapshott, "In quest of legitimacy: the theoretical and methodological foundations of entrepreneurship education research," International Small Business Journal: Researching Entrepreneurship, vol. 34, no. 7, pp. 895-904, 2016.

[14] G. Nabi, A. Walmsley, F. Liñán, I. Akhtar, and C. Neame, "Does entrepreneurship education in the first year of higher education develop entrepreneurial intentions? the role of learning and inspiration," Studies in Higher Education, vol. 43, no. 3, pp. 452-467, 2018.

[15] C. Thrane, P. Blenker, S. Korsgaard, and H. Neergaard, “The promise of entrepreneurship education: reconceptualizing the individual-opportunity nexus as a conceptual framework for entrepreneurship education," International Small Business Journal: Researching Entrepreneurship, vol. 34, no. 7, pp. 905-924, 2016.

[16] C. W. Utami, "Attitude, subjective norms, perceived behavior, entrepreneurship education and self-efficacy toward entrepreneurial intention university student in Indonesia," European Research Studies, vol. 20, no. 2, pp. 475-495, 2017.

[17] D. H. B. Welsh, W. L. Tullar, and H. Nemati, "Entrepreneurship education: process, method, or both?" Journal of Innovation \& Knowledge, vol. 1, no. 3, pp. 125-132, 2016.

[18] S. A. Macht, S. Ball, and M. Mccracken, "“Authentic Alignment"-a new framework of entrepreneurship education," Education + Training, vol. 58, no. 9, pp. 926-944, 2016.

[19] K. Fellnhofer and S. Kraus, "Examining attitudes towards entrepreneurship education: a comparative analysis among experts," International Journal of Entrepreneurial Venturing, vol. 7, no. 4, pp. 396-411, 2017.
[20] W. W. Kirkley, "Cultivating entrepreneurial behaviour: entrepreneurship education in secondary schools," Asia Pacific Journal of Innovation and Entrepreneurship, vol. 11, no. 1, pp. 17-37, 2017.

[21] T. Mets, I. Kozlinska, and M. Raudsaar, "Patterns in entrepreneurial competences as the perceived learning outcomes of entrepreneurship education," Industry and Higher Education, vol. 31, no. 1, pp. 23-33, 2017.

[22] S. Farny, S. H. Frederiksen, M. Hannibal, and S. Jones, "A Culture of entrepreneurship education," Entrepreneurship \& Regional Development, vol. 28, no. 7-8, pp. 514-535, 2016.

[23] J. R. Cornwall and W. J. Dennis, "Peeling the onion: public policy in entrepreneurship education," Journal of Entrepreneurship \& Public Policy, vol. 1, no. 1, pp. 12-21, 2016.

[24] K. Bischoff, C. K. Volkmann, and D. B. Audretsch, "Stakeholder collaboration in entrepreneurship education: an analysis of the entrepreneurial ecosystems of European higher educational institutions," The Journal of Technology Transfer, vol. 43, no. 1, pp. 20-46, 2018.

[25] J. Fox, L. Pittaway, and I. Uzuegbunam, "Simulations in entrepreneurship education: serious games and learning through play," Entrepreneurship Education and Pedagogy, vol. 1, no. 1, pp. 61-89, 2018. 